\title{
Mechanism of Lipid Accumulation through PAR2 Signaling in Diabetic Male Mice
}

\author{
Dae Hyun Kim, Ye Ra Kim, EunJin Bang, Sugyeong Ha, Sang Gyun Noh, Byeong Moo Kim, Seong Ho Jeong, \\ Hee Jin Jung, Ji Young Lee, Hae Young Chung \\ Department of Pharmacy, College of Pharmacy, Pusan National University, Busan, Korea
}

Background: Protease-activated protein-2 (PAR2) has been reported to regulate hepatic insulin resistance condition in type 2 diabetes mice. However, the mechanism of lipid metabolism through PAR2 in obesity mice have not yet been examined. In liver, Forkhead box O1 (FoxO1) activity induces peroxisome proliferator-activated receptor $\gamma$ (PPAR $\gamma$ ), leading to accumulation of lipids and hyperlipidemia. Hyperlipidemia significantly influence hepatic steatoses, but the mechanisms underlying PAR2 signaling are complex and have not yet been elucidated.

Methods: To examine the modulatory action of FoxO1 and its altered interaction with PPAR $\gamma$, we utilized $d b / d b$ mice and PAR2knockout (KO) mice administered with high-fat diet (HFD).

Results: Here, we demonstrated that PAR2 was overexpressed and regulated downstream gene expressions in $d b / d b$ but not in $d b^{+}$ mice. The interaction between PAR2/ $\beta$-arrestin and Akt was also greater in $d b / d b$ mice. The Akt inhibition increased FoxO1 activity and subsequently PPAR $\gamma$ gene in the livers that led to hepatic lipid accumulation. Our data showed that FoxO1 was negatively controlled by Akt signaling and consequently, the activity of a major lipogenesis-associated transcription factors such as PPAR $\gamma$ increased, leading to hepatic lipid accumulation through the PAR2 pathway under hyperglycemic conditions in mice. Furthermore, the association between PPAR $\gamma$ and FoxO1 was increased in hepatic steatosis condition in $d b / d b$ mice. However, HFD-fed PAR2-KO mice showed suppressed FoxO1-induced hepatic lipid accumulation compared with HFD-fed control groups.

Conclusion: Collectively, our results provide evidence that the interaction of FoxO1 with PPAR $\gamma$ promotes hepatic steatosis in mice. This might be due to defects in PAR2/ $\beta$-arrestin-mediated Akt signaling in diabetic and HFD-fed mice.

Keywords: Forkhead box protein O1; PPAR gamma; Receptor, PAR-2; Obesity; Fatty liver; Hyperlipidemia

\section{INTRODUCTION}

The global prevalence of obese population and associated metabolic diseases have significantly increased in these recent years $[1,2]$. The predisposition to the obesity appears different between genders, and this is majorly attributed to the different effects of sex hormones in adipose tissue metabolism [3,4]. Fur-

Received: 25 September 2020, Revised: 9 November 2020 ,

Accepted: 4 January 2021

Corresponding author: Hae Young Chung

Department of Pharmacy, College of Pharmacy, Pusan National University,

2 Busandaehak-ro 63beon-gil, Geumjeong-gu, Busan 46241, Korea

Tel: +82-51-510-2814, Fax: +82-51-518-2821, E-mail: hyjung@pusan.ac.kr thermore, gender-related differences in types of cells in adipose tissue in addition to adipocytes contribute to disparity in obesity between genders. These different characteristics are due to the molecular modulatory action of sex hormones in addition to the $\mathrm{X}$ chromosome-specific genes. Various up-to-date research based on molecular studies and in vivo models have explained an important role of sex hormones and particular molecules on

Copyright $\odot 2021$ Korean Endocrine Society

This is an Open Access article distributed under the terms of the Creative Commons Attribution Non-Commercial License (https://creativecommons.org/ licenses/by-nc/4.0/) which permits unrestricted non-commercial use, distribution, and reproduction in any medium, provided the original work is properly cited. 
fat accumulation.

Forkhead transcription factors (FoxOs) exert key roles in the regulation of cell metabolism, apoptosis, and redox stress responses [5]. Additionally, FoxO families are partially involved in regulation of insulin resistance through inhibiting phosphoinositide 3-kinase (PI3K)/Akt pathway [6]. For example, Akt-mediated FoxOs inactivates, and their shuttling from the nucleus to cytoplasmic fraction [7,8]. Moreover, increased intracellular reactive oxygen species levels and fatty acids contents promote FoxOs activation through a particular signaling mechanism, for example, through c-Jun N-terminal kinase (JNK) signaling $[9,10]$. However, forkhead box O1 (FoxO1) is involved in glucose metabolism. FoxO1-overexpressed mice demonstrated a diabetic phenotype by decreasing of genes that regulate insulin sensitivity in metabolic organ such as liver and adipocytes [11].

Peroxisome proliferator-activated receptors (PPARs) is one of nuclear hormone receptors transcription factors that are modulated by ligand. PPARs form heterodimer with retinoid X receptors (RXRs) and bind to PPAR response elements (PPRE) in the promoter region of particular target genes, leading to increased gene expressions. As of now, three subtypes of PPARs that are $\operatorname{PPAR} \alpha, \operatorname{PPAR} \beta$, and PPAR $\gamma$ have been found. In particular, PPAR $\gamma$ controls lipid accumulation by regulating transcription of adipocyte-released molecules and adipocytokines including adiponectin and leptin in order to decrease lipotoxicity in adipocytes [12] and hepatic lipid metabolism [13,14]. Kim et al. [15] reported that hepatic FoxO regulates genes that promote insulin resistance in the liver, consequently inducing hepatic lipogenesis and increasing hepatic fat content in diabetic mice model such as $d b / d b$ mice.

The function of FoxO1 is widely recognized in regulating genes involved in gluconeogenesis, but its regulatory role in lipid metabolism in the liver remains not fully known. As previous study has indicated that the overexpression of a constitutively active form of FoxO1 induces hepatic triglyceride (TG) accumulation [16], although there are other studies that have not replicated this result. Interestingly, FoxO1 inhibits the differentiation of adipocytes through PPAR $\gamma$ [17] and a number of research results have demonstrated that FoxO1 binds to promoter region of PPAR $\gamma$ and regulates its target gene expression [18]. Future studies are required in order to understand the function of FoxO1 in controlling hepatic steatosis in obesity.

Obesity is a physiological condition with body fat accumulation caused by excessive food intake and/or lack of energy expenditure. According to the World Health Organization, at least
1 in 10 adult populations worldwide are obese. Obesity is closely associated with metabolic syndrome, leading to shortened life-span by increasing risk factors of various diseases including stroke, diabetes, cardiovascular diseases, and cancers [19]. Therefore, obesity prevention may be an important strategy to ameliorate metabolic syndrome including insulin resistance, dyslipidemia, and fatty liver.

Insulin resistance is a pathological status that cells do not respond to normal insulin stimulation to uptake and store glucose. Consequently, hyperglycemia and hyperinsulinemia inhibited glucose uptake in reaction to insulin circulating from tissues. Furthermore, the subsequent promotion in insulin release from pancreatic beta-cells is additional effort to maintain glucose homeostasis. Furthermore, insulin resistance is associated with elevated glucose and TG level, contributing to hyperglycemia and hypertriglyceridemia in diabetes [20]. The underlying mechanism of such insulin actions and its association to insulin resistance are is still unclear. To elucidate the mechanisms underlying insulin resistance, we aimed to study their relationships by understanding the new role of FoxO1 in protease-activated protein-2 (PAR2) signaling.

PAR2 is a G protein-coupled receptor family known to act a critical role in activation of mesenchymal cell and proinflammatory signaling and responses [21]. The tissue factor (TF)/ VII $\alpha$ complex could activate PAR2 leading to inflammatory response through cytokine production including interleukin 6 (IL6 ) and tumor necrosis factor- $\alpha(\mathrm{TNF}-\alpha)$. Furthermore, PAR2 could lead to insulin resistance by suppressing Akt signaling in adipose tissue [22] and recruitment of monocytes [23]. The activation of such action of PAR2 during progression of tissue injury and remodeling microenvironment could initiate lengthened pathological initiation of the PAR2 signaling pathway. Nevertheless, it is unclear whether FoxO1 is associated with steatosis mediated by PAR2 signaling in the livers of obese mice.

In the current study, we examined hepatic steatosis in association to hyperglycemia via FoxO1 interaction with PPAR $\gamma$ through the PAR2 pathway in the livers of diabetic mice, to understand a detailed molecular signaling pathway during PAR2 involvement in lipid accumulation.

\section{METHODS}

\section{Animals}

Six- and 9-week-old male or female C57BLKS/J-lean (wild type [WT]) and C57BLKS/J- $d b / d b$ mice were obtained from SLC (Hamamatsu, Japan). The purchased stains of mice were 
maintained under condition of a 12-hour light/dark cycle, $23^{\circ} \mathrm{C} \pm 1^{\circ} \mathrm{C}$ and $50 \% \pm 5 \%$ relative humidity, specific pathogenfree environment. The mice were sacrificed after 1 week.

Whole PAR2 knockout (KO) mice (homozygote, PAR2 ${ }^{-1-}$; strain: B6.Cg-F2rl1 $\left.{ }^{\text {tmlMslb }} / \mathrm{J}\right), 8$-week-old, were provided by Dr. Yu (Pusan National University, YangSan, Korea) [24]. The male mice ( $n=6$ per group) were fed with water vehicle and normal chow diet or $60 \%$ high-fat diet (HFD) for total 4 months period. Genotyping of mice was performed according to the Jackson Laboratory's protocol with minor modifications (Jackson Laboratory, Bar Harbor, ME, USA). DNA was extracted from tail samples using the QuickExtract ${ }^{\mathrm{TM}}$ DNA Extraction Solution 1.0 (Epicentre, Madison, WI, USA). Standard polymerase chain reaction (PCR) amplification of cDNA was carried out with nTaq $\left(\mathrm{Mg}^{2+}\right.$ plus) DNA polymerase (Enzynomics, Daejeon, Korea) and specific primers. The primer sequences for genotyping PAR2 KO mice were as follows: mutant, 5' - GCC AGA GGC CAC TTG TGT AG -3'; WT forward, 5' - TCA AAG ACT GCT GGT GGT TG-3'; WT reverse, 5' - GGT CCA ACA GTA AGG CTG CT-3'. PCR products were separated on a $1.5 \%$ agarose gel, visualized, and photographed under ultraviolet light. The animal protocol for this study was approved by the Pusan National University Institutional Animal Care and Use Committee (PNU-IACUC-2019-2197; PNU-IACUC-2019-2280) under guideline of ethics and animal care.

\section{Materials}

The chemicals for Western blotting were purchased from Amersham (Bucks, UK). RNAzol ${ }^{\mathrm{TM}} \mathrm{B}$ was purchased from TELTEST Inc. (Friendwood, TX, USA). Primary antibodies against FoxO1, glyceraldehyde-3-phosphate dehydrogenase (GAPDH), transcription factor IIB (TFIIB), tyrosine reside phosphorylation of insulin receptor substrate (p-IRS (Tyr632)), p-IRS (Ser307), phosphorylation-serine/threonine protein kinase ( $\mathrm{p}$-Akt), total Akt, peroxisome proliferator-activated receptor-alpha (PPAR $\alpha$ ), PPAR $\beta, \operatorname{PPAR} \gamma, \beta$-arrestin, phosphorylation-AMP-activated protein kinase ( $\mathrm{p}$-AMPK), AMPK, sterol regulatory elementbinding protein 1c (SREBP-1c), and PAR2 were purchased from Santa Cruz Biotechnology (Santa Cruz, CA, USA). Primary antibodies against p-FoxO1 (Thr24) and p-FoxO1 (Ser256) were manufactured by Cell Signaling Technology, Inc. (Danvers, MA, USA). Secondary antibodies, both anti-rabbit and anti-mouse immunoglobulin $\mathrm{G}$ (IgG)-horseradish peroxidase-conjugated antibodies, were purchased from Amersham. Horseradish peroxidase-conjugated donkey anti-sheep/goat IgG was obtained from Serotec (Oxford, UK). Polyvinylidene diflu- oride (PVDF) transfer membranes were obtained from manufacturer Millipore Corporation (Bedford, MA, USA).

\section{Nuclear extract preparation}

Frozen mouse liver tissues $(20 \mathrm{mg}$ ) were washed in phosphate buffered saline (PBS) buffer and then were subject to a Dounce tissue grinder (Wheaton Manufacturers, Millville, NJ, USA). Solution A (10 mM 4-(2-hydroxyethyl)-1-piperazineethanesulfonic acid [HEPES] $\mathrm{pH} 7.9,10 \mathrm{mM} \mathrm{KCl}, 0.1 \mathrm{mM}$ ethylenediamine tetraacetic acid [EDTA], $0.1 \mathrm{mM}$ ethylene glycol-bis $(\beta$ aminoethyl ether)- $N, N, N^{\prime}, N^{\prime}$-tetraacetic acid [EGTA], $0.5 \mathrm{mM}$ phenylmethylsulfonyl fluoride [PMSF], and $1 \mathrm{mM}$ dithiothreitol [DTT]) was then added to the tissues $(2.5 \mathrm{~g} / \mathrm{mL})$. Tissues were stressed and homogenized with five hits of a pestle after addition of NP-40 (0.5\%) and then further homogenized with five more strokes. Liver homogenates were transferred to 1.5 $\mathrm{mL}$ Eppendorf tubes and centrifuged using a microcentrifuge (Beckman, Brea, CA, USA) for 5 minutes at 12,000 rpm.

Supernatants is majorly comprised of cytoplasmic constituents. To have nuclear pellets, $400 \mu \mathrm{L}$ of solution $\mathrm{C}(20 \mathrm{mM}$ HEPES pH 7.9, $0.4 \mathrm{M} \mathrm{NaCl}, 1 \mathrm{mM}$ of each of EDTA, EGTA, PMSF, and DTT) was added to the supernatants. Tube contents were blended thoroughly and set on a small rotatory shaker for 15 minutes. Finally, they were centrifuged for 10 minutes at $12,000 \mathrm{rpm}$ in a microcentrifuge. The supernatants, which contained nuclear proteins, were transferred carefully to $1.5 \mathrm{~mL}$ new tubes, and kept at $-80^{\circ} \mathrm{C}$ until required for Western blotting. Protein concentrations were determined using the bicinchoninic acid (BCA) protein assay (Sigma, St. Louis, MO, USA).

\section{Western blotting}

Homogenized samples were boiled for 5 minutes with a gelloading buffer (125 mM Tris-Cl, 4\% SDS, 10\% 2-mercaptoethanol, $\mathrm{pH} 6.8$, and $0.2 \%$ bromophenol blue) at a ratio of $1: 1$. The same amounts of protein were separated by sodium dodecyl sulfate-polyacrylamide gel electrophoresis, using $6 \%$ to $17 \%$ separating running gels and then proteins were transferred to PVDF membranes at $15 \mathrm{~V}$ for 1 hour using a semi-dry transfer method. Immediately, the membrane was immersed in a blocking buffer containing $10 \mathrm{mM}$ Tris ( $\mathrm{pH} 7.5), 100 \mathrm{mM} \mathrm{NaCl}$, and $0.1 \%$ Tween-20 containing 1\% non-fat milk. Membranes were blocked for 1 hour at room temperature, and the membranes were incubated and proteins were probed with the appropriate specific primary antibody at $25^{\circ} \mathrm{C}$ for 1 hour, subsequently followed by horseradish peroxidase-conjugated secondary anti- 
body at $25^{\circ} \mathrm{C}$ for another 1 hour. Antibody labeling was detected using enhanced chemiluminescence in accordance to the manufacturer's instructions. Molecular weights were determined using pre-stained lane protein markers.

\section{Serum biochemical analysis}

Serum glucose concentration was measured using kits from Bioassay Systems (Hayward, CA, USA). Specific kits were used, following the manufacturer's protocols, to measure the concentrations of insulin (Shibayagi, Japan).

\section{Immunoprecipitation of nuclear extracts}

Cytosol or nuclear extract fractions were immunoprecipitated in a immunoprecipitation (IP) buffer comprised of $40 \mathrm{mM}$ Tris$\mathrm{HCl}$ ( $\mathrm{pH}$ 7.6), $120 \mathrm{mM} \mathrm{NaCl}, 20 \mathrm{mM} \beta$-glycerophosphate, 20 $\mathrm{mM}$ NaF, $2 \mathrm{mM}$ sodium orthovanadate, $1 \mathrm{mM}$ PMSF, $5 \mathrm{mM}$ EDTA, $0.1 \%$ NP-40, leupeptin $(2 \mu \mathrm{g} / \mathrm{mL})$, aprotinin $(1 \mu \mathrm{g} / \mathrm{mL})$, and pepstatin $\mathrm{A}(1 \mu \mathrm{g} / \mathrm{mL})$. Aliquots of cytosol or nuclear extracts were than pre-cleared by using $50 \%$ protein A agarose for 30 minutes at $4^{\circ} \mathrm{C}$, centrifuged at $12,000 \times \mathrm{g}$ at $4^{\circ} \mathrm{C}$ for $15 \mathrm{~min}-$ utes, incubated overnight at $4^{\circ} \mathrm{C}$ with the appropriate antibody, and then incubated overnight at $4{ }^{\circ} \mathrm{C}$ with a $50 \%$ protein $\mathrm{A}$ agarose slurry. After washing the immunoprecipitates three times with an IP buffer, immunoprecipitated proteins were detected using sodium dodecyl sulfate-polyacrylamide gel electrophoresis (SDS-PAGE); Western blotting analysis was performed as described above.

\section{Hepatic lipid content}

Liver tissues were thoroughly homogenized in PBS. TGs were extracted with a 1:2 methanol-chloroform solution by incubating at room temperature for 2 hours. After filtering out impurities using a filter, the TG liquid solvent was evaporated. The TG levels were assessed using a kit (Bioassay Systems).

\section{RNA isolation and real-time reverse transcriptase polymerase chain reaction}

RNA isolation from mouse liver tissues $(20 \mathrm{mg})$ was performed using the RNeasy Mini Kit (Qiagen, Hilden, Germany). Quantitative reverse transcriptase polymerase chain reaction (qRTPCR) analysis was performed to quantify mRNA levels using the SYBR Green and CFX Connect System (Bio-Rad Laboratories Inc., Hercules, CA, USA). All primers were designed and purchased from Integrated DNA Technologies (Coralville, IA, USA). The primers sequence used are listed in Supplemental Table S1.

\section{Statistical analysis}

Analysis of variance (ANOVA) was used in order to determine the statistical significance of the differences between the groups. Fisher's protected least significant difference post hoc test was used to test the significant difference between group means. $P$ values $<0.05$ were cutoff to indicate statistical significance.

\section{RESULTS}

\section{Changes in glucose and lipid metabolism in diabetic mice} Obesity changes blood lipid levels, which are highly related with hepatic steatosis [25]. Liver weight increased in diabetic mice (Fig. 1A), and blood lipid profiles were investigated in $\mathrm{db}$ / $d b$ mice. Glucose level significantly elevated glucose levels in mice (Fig. 1B). Furthermore, hyperinsulinemia significantly elevated insulin in the serum, compared to age-matched animals (Fig. 1C). Our data suggest that obesity induced hyperinsulemia and hyperglycemia in diabetic mice.

\section{Modulation of both FoxO1 and PPARs in the livers of diabetic mice}

To confirm potential changes hepatic lipid accumulation in obesity, we measured the TG concentration in liver tissues. The contents of hepatic TG were significantly increased in agematched male $d b / d b$ mice (Fig. 2A). In addition, female $d b / d b$ mice had increase in hepatic TG content, while male $d b / d b$ mice showed no increasing tendency (Supplemental Fig. S1). Therefore, we further focus on male $d b / d b$ mice and investigated its mechanism of hepatic steatosis.

FoxO1 is majorly suppressed by Akt during insulin signaling activation. FoxO1 shuttling from the nucleus to cytoplasmic fraction by Akt, inhibiting its action as its role as a transcription factor [26]. We found that FoxO1 phosphorylation level was reduced in the liver of diabetic $d b / d b$ mice (Fig. 2B). In addition, the nuclear protein levels of PPAR $\beta$ were found to be decreased in the liver of diabetic mice in comparison to that of the normal mice. In contrast, nuclear PPAR $\gamma$ levels were notably increased. However, lipogenic gene SREBP-1c level was increased in $\mathrm{db}$ / $d b$ mice (Fig. 2C). Based on the IP experiments, the physical association between FoxO1 and PPAR $\gamma$ was shown to be induced in $d b / d b$ mice liver (Fig. 2D). Furthermore, the modulatory action of FoxO1 as a regulator of lipogenic genes was explored in association with the obesity. Diabetic mice exhibited remarkably higher mRNA levels of PPAR $\gamma$, whereas the transcripts of $\beta$-oxidation genes, such as PPAR $\alpha$ and $\operatorname{PPAR} \beta$, did not alter (Fig. 2E). The expression levels of target lipogenic genes of 

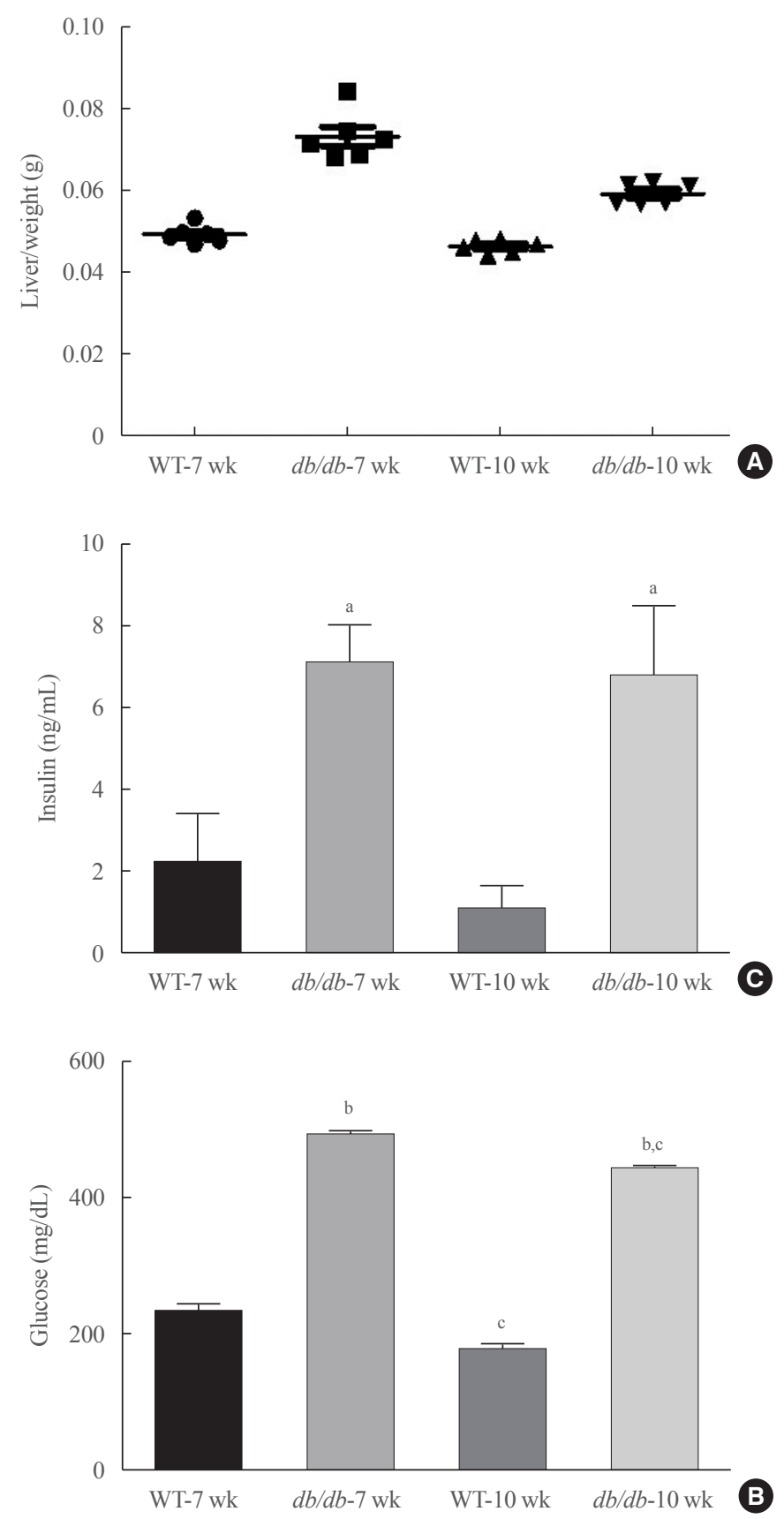

Fig. 1. Obesity-dependent serum changes in insulin resistance and lipogenesis. (A) Liver weight. (B) Fasting glucose levels. (C) Insulin levels measured in the serum of $d b / d b$ mice (each $n=6$ ). Results represents three independent experiments for each protein. Statistical results of one-factor analysis of variance. WT, wild type. ${ }^{\mathrm{a}} P<0.01,{ }^{\mathrm{b}} P<0.001$ vs. WT mice; ${ }^{\mathrm{c}} P<0.01$ vs. 7 -week mice.

PPAR $\gamma$, such as fatty acid synthase (FASN), acetyl-CoA carboxylase (ACC), and stearoyl-CoA desaturase 1 (SCD1), were correlated to PPAR $\gamma$ expression levels and increased in $d b / d b$ mice in comparison to those of control $d b^{+}$mice (Fig. 2F). In contrast, the expression levels of PPAR $\alpha$ target genes remained unchanged in $d b / d b$ mouse livers (Fig. 2G). These data collectively indicate that in the liver of $d b / d b$ mice, the greater interaction between FoxO1 and PPAR $\gamma$ was induced and resulted in upregulated lipid accumulation in liver of $d b / d b$ mice.

\section{Change of insulin signaling in obesity mice}

As fasting glucose contents are majorly modulated by insulin in the liver, we investigated insulin signaling in the livers of $d b / d b$ mice. As demonstrated in Fig. 3, insulin resistance marker, pIRS1 (Ser307) was notably upregulated in age-matched $d b / d b$ mice, whereas the concentration of Ser473-phosphorylated Akt were found to be decreased in $d b / d b$ mice (Fig. 3A). AMPK is widely recognized to be a key regulator of fatty acid and glucose homeostasis. We next investigated whether obesity modulates AMPK. As shown in Fig 3B, obesity mice significantly decreased the phosphorylation of AMPK.

\section{Interaction of PAR2 and $\beta$-arrestin in $d b / d b$ mice}

PAR2 plays a critical role in inflammatory response and steatosis in liver [27]. Up to now, there found four isoforms of PARs, PAR1-4. Particularly, PAR2 becomes activated by trypsin-like proteases including tryptase. In addition, PAR2 signaling becomes initiated by coagulation factors VII $\alpha$ and X $\alpha$ in TF expression.

Our previously reported PAR2 expression becomes upregulated in the liver of FoxO6-transgenic mice compare with another PAR family [28]. To find whether PAR2 acts a regulatory role in insulin resistance in vivo, we studied PAR2 and $\beta$-arrestin expression in $d b / d b$ mice. PAR 2 and $\beta$-arrestin expression was increased in $d b / d b$ mice (Fig. 4A). In the IP experiments, PAR2 and $\beta$-arrestin were observed to interact in $d b / d b$ mice: PAR2 and $\beta$-arrestin strongly interacted with each other in $d b / d b$ mice (Fig. 4B). Furthermore, we found weak interactions between $\beta$-arrestin and Akt in $d b^{+}$mice (Fig. 4C).

\section{Serum changes in HFD-mediated PAR2-KO mice}

Blood lipid profiles were investigated in HFD-feeding PAR2$\mathrm{KO}$ mice. Hyperglycemia was significantly elevated glucose level in HFD-mice (Fig. 5A). Otherwise, glucose level no changed in HFD-PAR2-KO compare with HFD groups. However, HFD-induced hypertriglyceridemia significantly elevated, as compared with WT chow. However, TG levels reduced in HFD-feeding PAR2-KO compared with HFD-feeding mice (Fig. 5B). Otherwise, no differences were found in the levels of non-esterified fatty acids (NEFA) (Fig. 5C). 

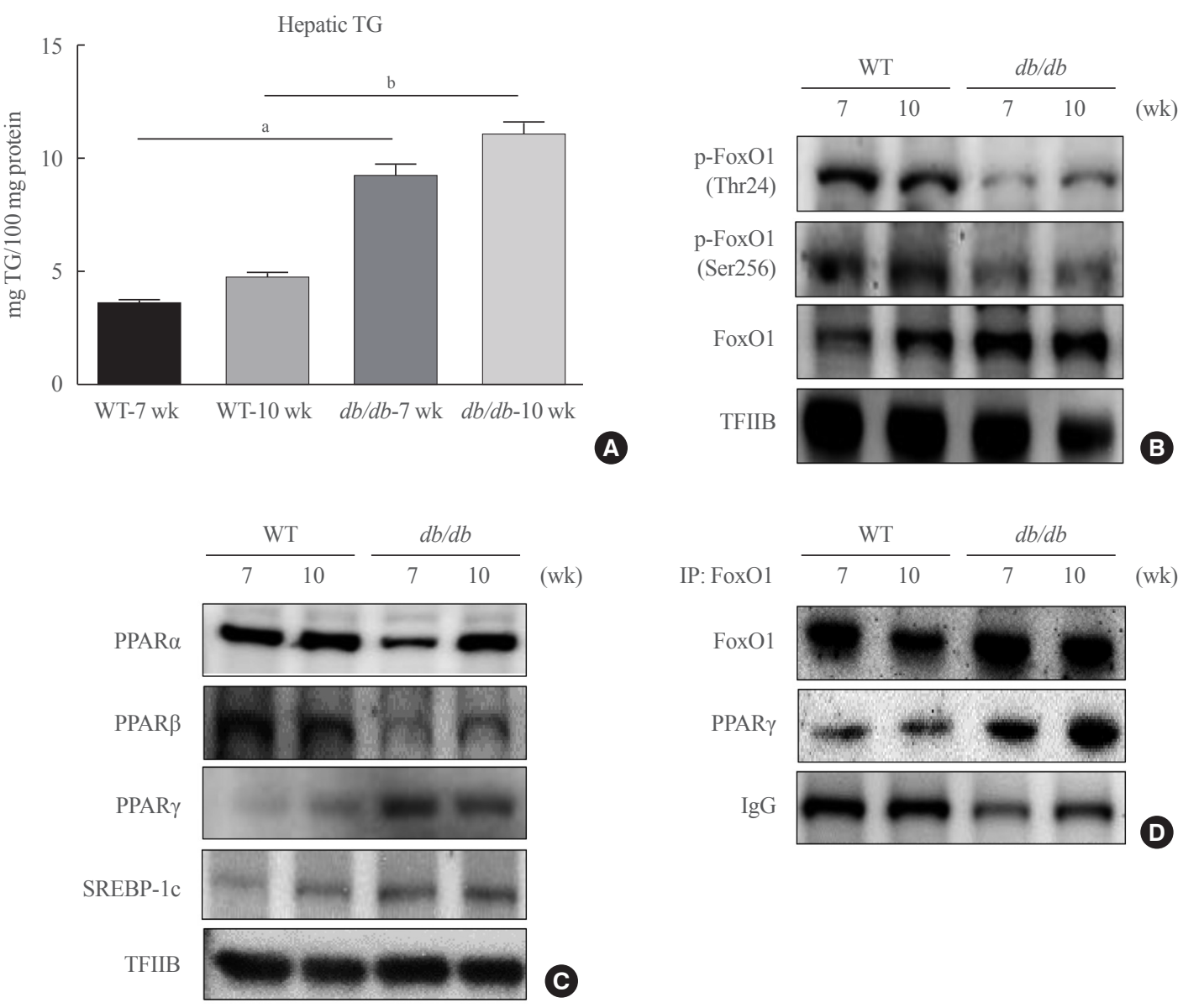

$\operatorname{PPAR} \gamma$

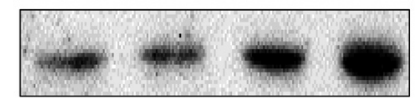

IgG

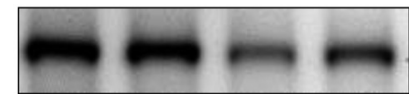

D
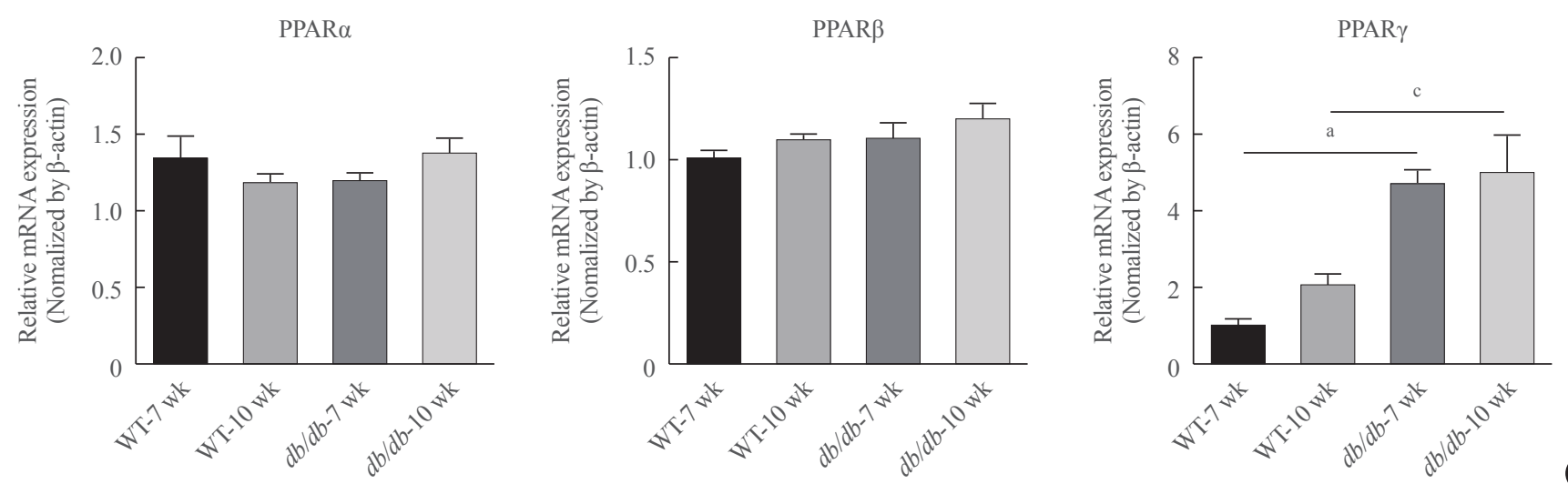

Fig. 2. Obesity increase in Forkhead box O1 (FoxO1)-induced lipid accumulation. (A) Hepatic triglyceride (TG) in male $d b / d b$ mice. One representative result of three experiments yielding similar outcomes for each protein is listed. Results of one-factor analysis of variance (ANOVA). (B) Western blotting was conducted to find the protein levels of p-FoxO1 and FoxO1 in $d b / d b$ mice liver. Transcription factor II $\mathrm{B}$ (TFIIB) was used as the loading control protein of the nuclear fraction. (C) Western blotting of peroxisome proliferator-activated receptors (PPARs) and sterol regulatory element-binding protein 1c (SREBP-1c) in the nucleus of $d b / d b$ mouse livers. TFIIB was used as the loading control of the nuclear fraction. (D) Western blotting showed that immunoprecipitated FoxO1 and PPAR $\gamma$ interacted with PPAR $\gamma$ and FoxO1, respectively. (E) Real-time polymerase chain reaction analysis was performed for analyzing the mRNA levels of PPAR $\alpha$, PPAR $\beta$, and PPAR $\gamma$. Results of one-factor ANOVA.

(Continued to the next page) 

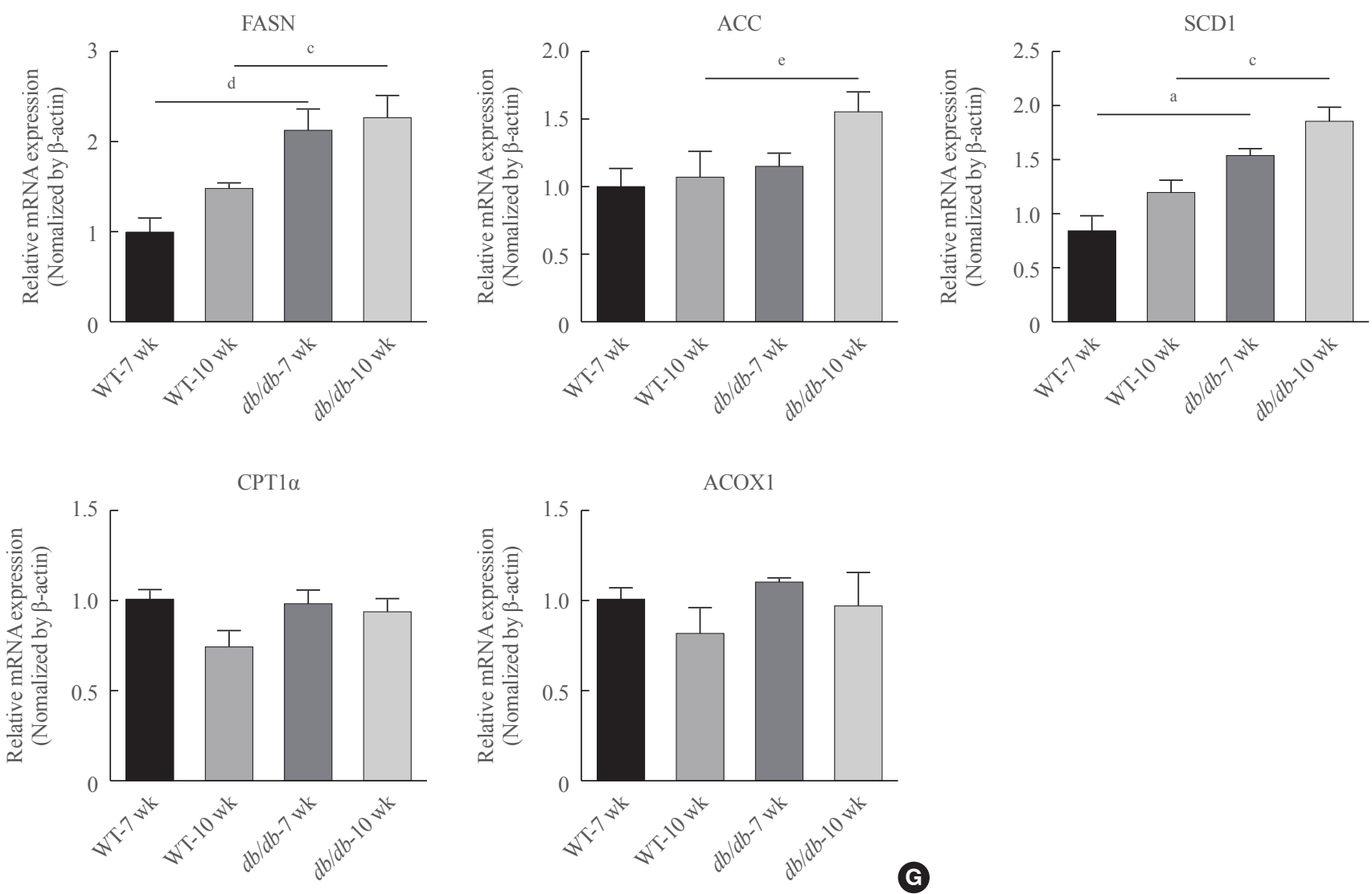

Fig. 2. Continued. (F) Real-time PCR analysis was conducted for analyzing the mRNA expression levels of fatty acid synthase (FASN), acetyl-CoA carboxylase (ACC), and stearoyl-CoA desaturase 1 (SCD1). Results of one-factor ANOVA. (G) Real-time PCR analysis was performed for analyzing the mRNA levels of carnitine palmitoyltransferase I $\alpha(\mathrm{CPT} 1 \alpha)$ and peroxisomal acyl-coenzyme A oxidase 1 (ACOX1). IgG, immunoglobulin G; WT, wild type. ${ }^{\mathrm{a}} P<0.001$ vs. 7 weeks $d b^{+}$mice; ${ }^{\mathrm{b}} P<0.001$ vs. 10 weeks $d b^{+}$mice; ${ }^{\mathrm{c}} P<0.01$ vs. 10 weeks $d b^{+}$mice; ${ }^{\mathrm{d}} P<0.01$ vs. 7 weeks $d b^{+}$mice; ${ }^{\mathrm{e}} P<0.05$ vs. 10 weeks $d b^{+}$mice.

\section{Relationship between PAR2 and hepatic steatosis with FoxO1}

HFD-mediated insulin resistance condition was notably promoted and positively associated with the pathogenesis of hyperlipidemia. We investigated PAR2 pathway during hepatic steatosis in HFD-fed PAR2-KO mice. As shown in Fig. 6, we investigated whether PAR2 modulate lipid accumulation in the livers of HFD-feeding mice. This result that FoxO1 activation was induced in HFD-feeding groups. However, nuclear protein levels of PPAR $\gamma$ level was increased in HFD-feeding animals. On the other hand, PPAR $\gamma$ protein expression was reduced HFD-PAR2-KO mice compared with HFD-feeding groups (Fig. 6A). Moreover, to confirm potential PAR2-regulated changes in hepatic lipid accumulation, we measured the TG concentration in liver tissue. This result that the contents of hepatic TG were significantly reduced in HFD-feeding PAR2-KO mice compared with HFD-feeding groups (Fig. 6B). However, PPAR $\gamma$ and its target genes, such as FASN, ACC, and SCD1, which was additively increased HFD-feeding groups, and PPAR $\gamma$, FASN, and SCD1 was reduced in HFD-feeding PAR2-KO compared with HFD-feeding groups (Fig. 6C). These results showed that PAR2 promoted stimulatory effect on lipid accumulation in HFD-mediated groups.

\section{DISCUSSION}

This study investigated a change in association between FoxO1 and PPAR $\gamma$ that mediates hepatic steatosis in obesity. Reportedly, FoxO1 ameliorates insulin signaling in liver and fatty liver disease, even though its underlying signaling mechanisms remain to be further examined [29,30]. Here, we studied the molecular signaling mechanism through which FoxO1 improves hepatic steatosis condition in obesity. Our data suggested that hyperinsulinemia impaired insulin signaling in $d b / d b$ mouse 

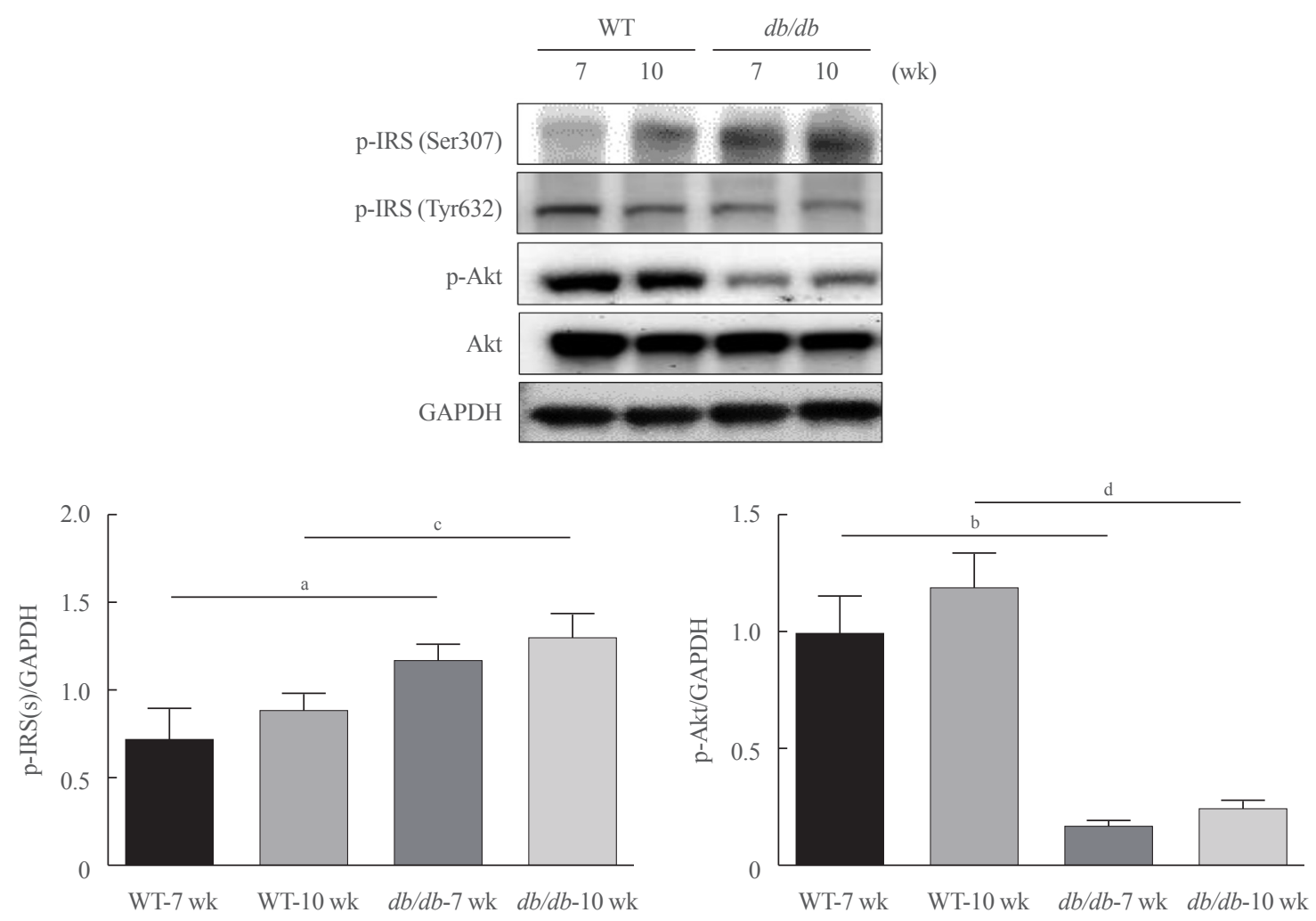

\section{A}

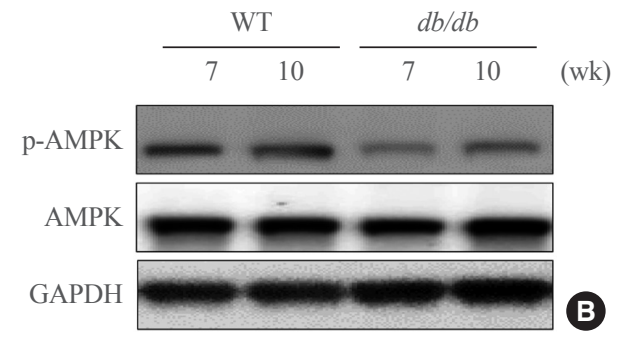

Fig. 3. Changes in insulin signaling in $d b / d b$ mice. (A)Western blotting was conducted in order to detect the protein expression levels of the factors involved in insulin signaling and Akt signaling. Obesity-related insulin signaling factors phospho-serine-insulin receptor substrate 1 (pSer-IRS1), phospho-tyrosine-insulin receptor substrate 1 (pTyr-IRS1), p-Akt, and total Akt levels. Glyceraldehyde 3-phosphate dehydrogenase (GAPDH) was used as the loading control protein of the cytoplasm. Results are representative of three independent experiments for each protein. Results of one-factor analysis of variance. (B) Western blot analysis was performed to detect protein levels of phospho-AMPactivated protein kinase (p-AMPK), and AMPK in liver homogenates. GAPDH was used as the loading control protein of the cytoplasm. WT, wild type. ${ }^{\mathrm{a}} P<0.05,{ }^{\mathrm{b}} P<0.001$ vs. 7 weeks $d b^{+}$mice; ${ }^{\mathrm{c}} P<0.05$, ${ }^{\mathrm{d}} P<0.001$ vs. 10 weeks $d b^{+}$mice.

models (Fig. 3). We found that FoxO1 induced PPAR $\gamma$ mediated lipid accumulation through a hyperinsulinemia-mediated PAR2 pathway, and the Akt level decreased and FoxO1 was de-phosphorylated in the livers of obese mice (Fig. 2). Insulin resistance have not been previously investigated in HFDfeeding PAR2-KO. We consider that the alterations in lipid metabolic profile were partially controlled by hyperinsulinemia in obesity mouse.
FoxOs are critical downstream target transcription factors through insulin signaling and have been suggested to affect longevity by increased intracellular oxidative stress, both of which are potential factors that can lead to obesity acceleration [31,32]. On the other hand, modulatory effects on anti-oxidation are regulated by FoxO family, which, under condition lacking insulin signaling, it bind to promoters of antioxidant enzymes genes and upregulates and such gene transcription [33]. These and 


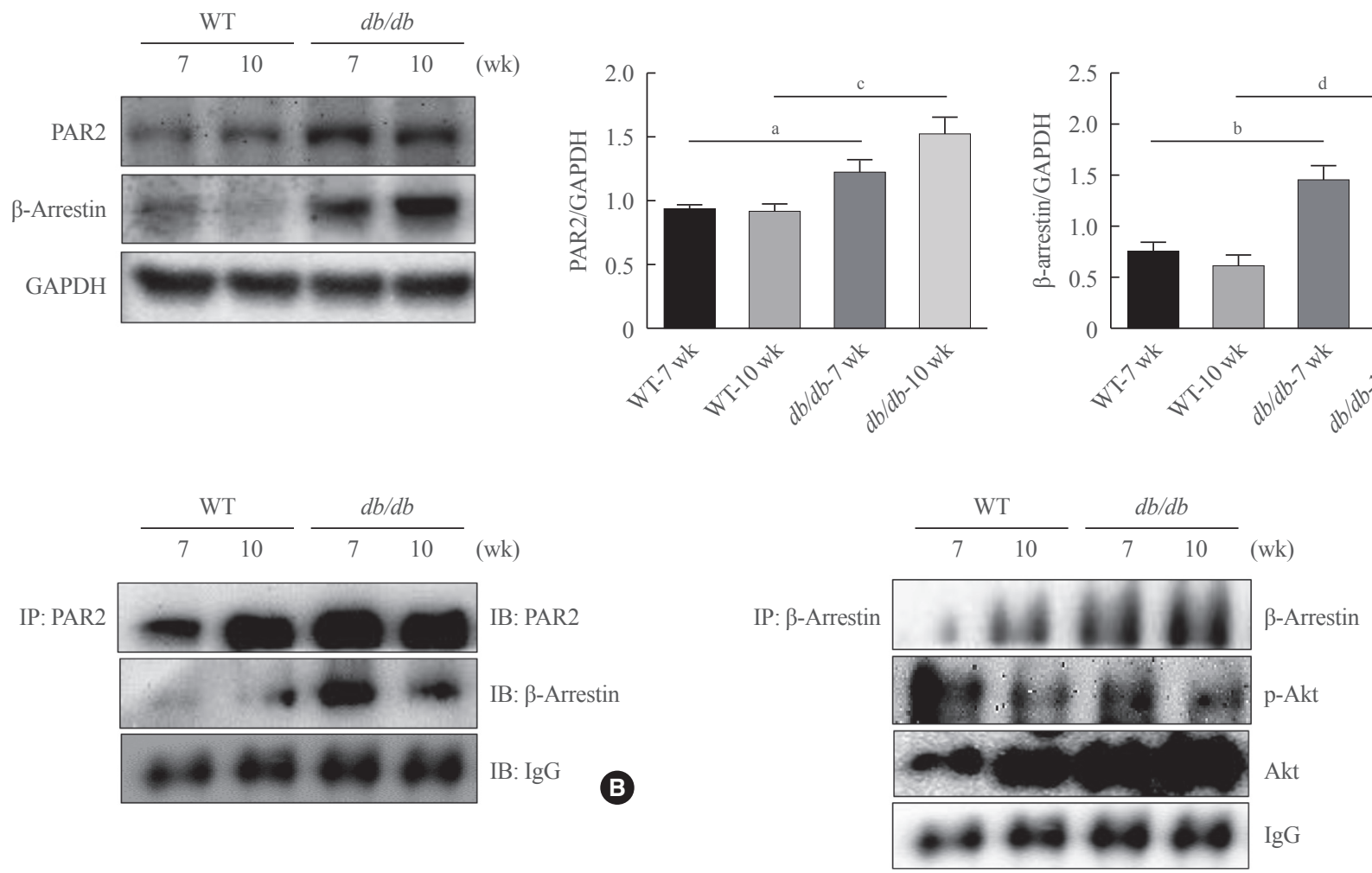

C

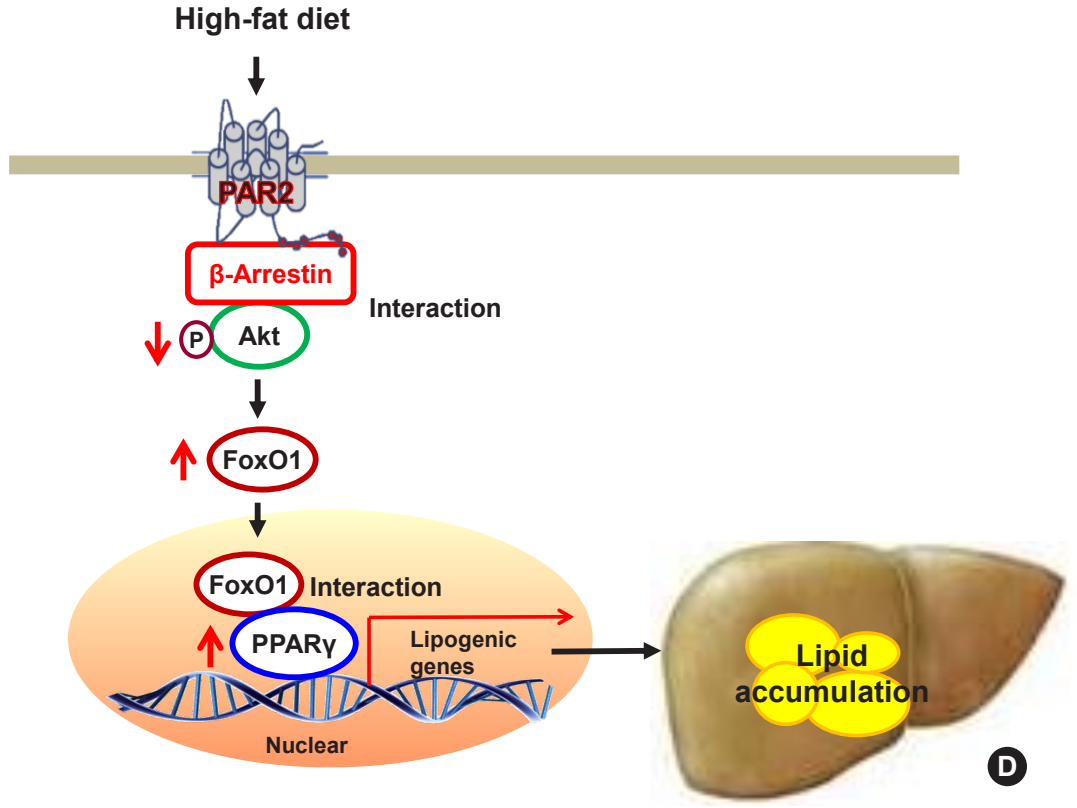

Fig. 4. Interaction of protease-activated protein-2 (PAR2) and $\beta$-arrestin in $d b / d b$ mice. (A) PAR2 and $\beta$-arrestin concentrations were analyzed using cytosolic fraction extracted from the liver samples of $d b / d b$ mice. Glyceraldehyde 3-phosphate dehydrogenase (GAPDH) was used as the loading control protein of the cytosolic fractions. Results of one-factor analysis of variance. (B) Western blotting showed that immunoprecipitated PAR2 and $\beta$-arrestin were physically interacted with PAR2 and $\beta$-arrestin, respectively. (C) Western blotting showed that immunoprecipitated $\beta$-arrestin and Akt were interact with $\beta$-arrestin and Akt, respectively. (D) A potential mechanism underlying the effect of Forkhead box O1 (FoxO1) on PAR2/ $\beta$-arrestin signaling in obesity. WT, wild type; IP, immunoprecipitation; IB, immunoblotting; IgG, immunoglobulin G; FoxO1, forkhead box O1; PPAR $\gamma$, peroxisome proliferator-activated receptor $\gamma .{ }^{\mathrm{a}} P<0.05,{ }^{\mathrm{b}} P<0.01$ vs. 7 weeks $d b^{+}$ mice; ${ }^{\mathrm{c}} P<0.01,{ }^{\mathrm{d}} P<0.001$ vs. 10 weeks $d b^{+}$mice. 

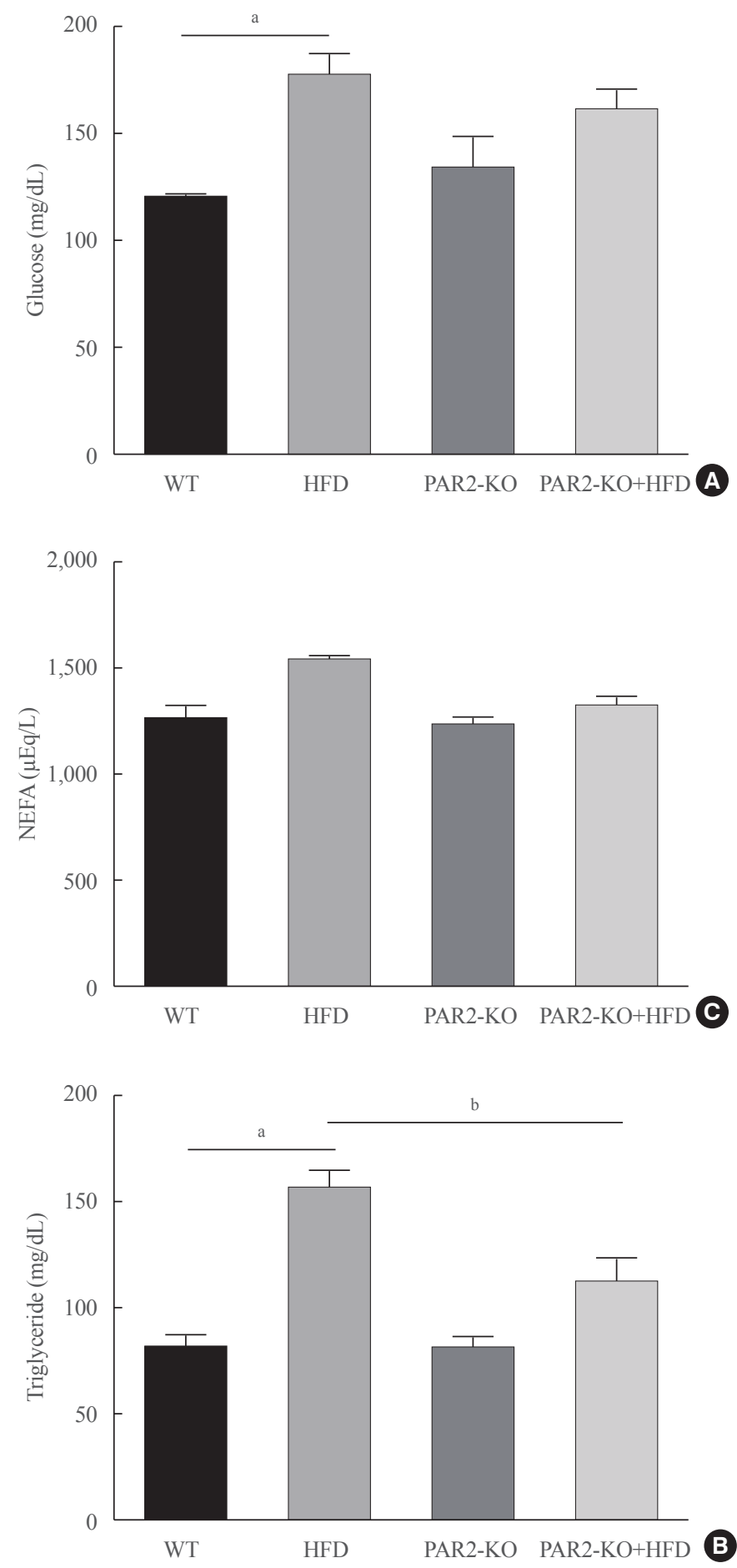

Fig. 5. High-fat diet (HFD)-mediated serum changes in proteaseactivated protein-2 (PAR2)-knockout (KO) mice. (A) Fasting glucose levels, (B) triglycerides, (C) free fatty acids level in the serum of HFD-feeding PAR2-KO mice (each $n=6$ ). One representative result of three experiments yielding similar outcomes for each protein is demonstrated. Results of one-factor analysis of variance. WT, wild type; NEFA, non-esterified fatty acid. a $P<0.01$ vs. WT chop mice; ${ }^{b} P<0.05$ vs. HFD-feeding mice. other findings strongly suggest the involvement of FoxO1 in the progression of diabetes.

Lipogenesis-related transcription factor PPAR $\gamma$ was induced by FoxO1 in $d b / d b$ mice (Fig. 2E). Since FoxO1 and PPAR $\gamma$ are closely associated with hepatic steatosis [29,34,35], this study provided substantial evidence that hepatic steatosis was induced FoxO1-induced PPAR $\gamma$ upregulation through hyperinsulinemia. Consistently, FoxO1-mediated lipogenesis enhanced hepatic lipid accumulation under these conditions (Fig. 2A). It is well reported that PPAR $\gamma$ induces hepatic lipid accumulation [3638]. PPAR $\gamma$ expression upregulation is involved in steatosis in liver through the upregulation of lipogenic gene transcription and subsequently expression in obese mice [34,36,38]. Consistent with such findings, liver-specific deletion of PPAR $\gamma$ in $d b$ / $d b$ mice has been found to markedly ameliorate steatosis in liver by downregulating ACC, SCD1, and FAS [37], although diverse research results have demonstrated [18] that both FoxO1 and PPAR $\gamma$ stimulate hepatic steatosis. The capability of FoxO1 to control inflammatory response exert a pivotal role in numbers of metabolic diseases, for example, obesity, insulin resistance, hyperlipidemia, and nonalcoholic fatty liver disease [39], although its incidence in metabolic syndrome is correlated with a high-fat containing dietary habits or extreme calorie intake [40]. The association between aging and metabolic syndrome suggest that proinflammatory condition is critical risk factor for disease initiation and progression [41].

The results of our study demonstrated that the interaction between FoxO1 and PPAR $\gamma$ mediated hepatic lipid accumulation through the PAR2 pathway. We also investigated the cross-talk between $\beta$-arrestin and PAR2. Here, we were able to show that the interaction between PAR2/ $\beta$-arrestin and Akt was compared with $d b^{+}$, and PAR2 expression increased in $d b / d b$, as depicted in Fig. 4, indicating the essential role of PAR2 signaling pathway in hepatic and metabolic diseases associated with obesity. These data indicate that in males, the increase in PAR2 and $\beta$-arrestin interaction might be due to an increase in PAR2 expression and that it may, in part, adds to the increase in lipid accumulation in liver compared to that of $d b^{+}$mice. PAR2 expression was higher in $d b / d b$ compared to that in $d b^{+}$mice. PAR2 controls and activates critical negative signaling molecule gene expressions involved in primitive cell proliferation [42]. In addition, PAR2 signaling activation exerts a pivotal role in hepatic insulin resistance that subsequently leads to systemic steatosis in obesity [43]. However, we previously reported that FoxO6/ IL-1 $\beta /$ PAR2 axis may be involved in obese mice and the protein levels of FoxO6 and PAR2 were elevated with the increase in 

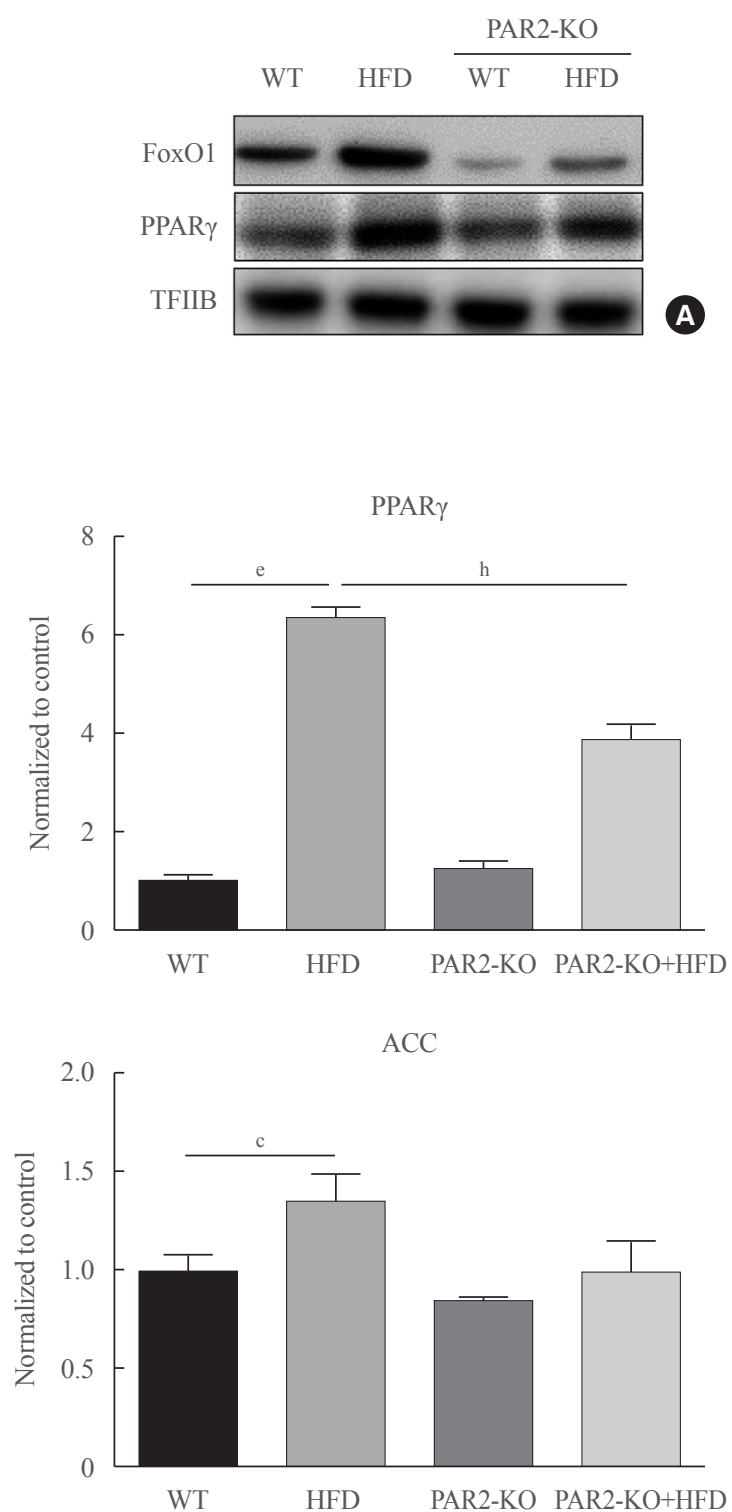
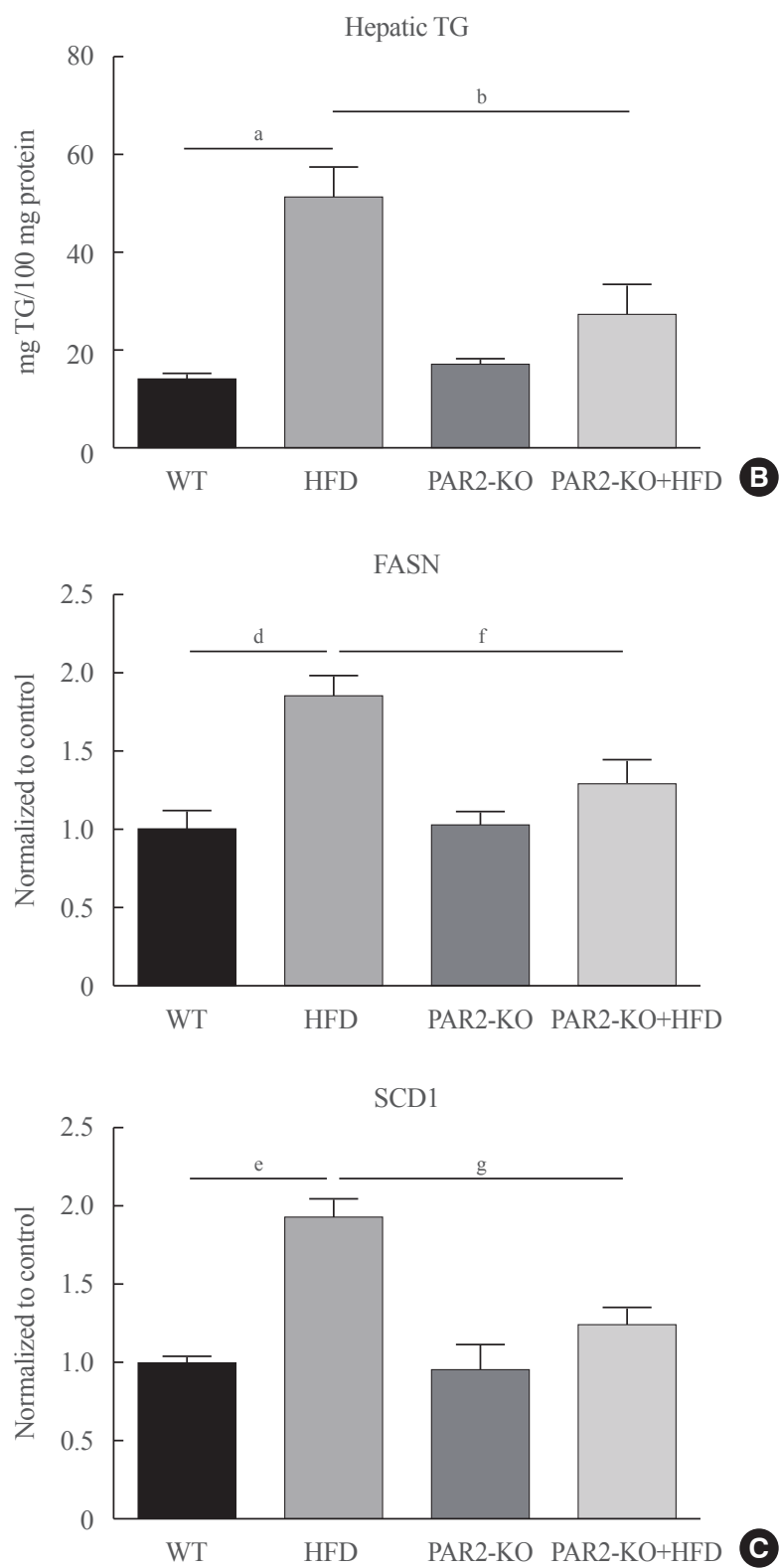

Fig. 6. Forkhead box O1 (FoxO1) induces hepatic steatosis in high-fat diet (HFD)-feeding protease-activated protein-2 (PAR2)-knockout (KO). Western blotting analyses of liver cytosolic fraction (A) FoxO1 and peroxisome proliferator-activated receptor $\gamma(\mathrm{PPAR} \gamma)$ concentrations were analyzed using nuclear proteins extracted from obese mice ( $n=6$ in each group). Transcription factor II B (TFIIB) was the loading control protein of the nuclear fractions. (B) Hepatic triglyceride (TG) in HFD-feeding PAR2-KO mice. One representative result of three experiments yielding similar outcomes for each protein is demonstrated. Results of one-factor analysis of variance (ANOVA). (C) Real-time polymerase chain reaction analyses was conducted for analyzing the mRNA levels of lipogenic genes such as PPAR $\gamma$, fatty acid synthase (FASN), acetyl-CoA carboxylase (ACC), and stearoyl-CoA desaturase 1 (SCD1). Results of one-factor ANOVA. WT, wild type. ${ }^{a} P<0.01$ vs. normal control mice; ${ }^{\mathrm{b}} P<0.05$ vs. HFD-feeding mice; ${ }^{\mathrm{c}} P<0.05,{ }^{\mathrm{d}} P<0.01,{ }^{\mathrm{e}} P<0.001$ vs. WT chow; ${ }^{\mathrm{f}} P<0.05,{ }^{\mathrm{g}} P<0.01,{ }^{\mathrm{h}} P<0.001$ vs. WTHFD.

the mRNA levels of IL-1 $\beta$ in the liver. These results indicate that FoxO6 is able to bind to the promoter of IL-1 $\beta$ and stimulate its transcription in insulin-resistant state [28].

HFD-induced insulin resistance was notably induced and positively associated with the pathogenesis of hyperlipidemia. TG levels reduced HFD-feeding PAR2-KO compare with HFDfeeding mice (Fig. 5). However, PAR2 had an enhanced stimulatory effect on lipid accumulation through FoxO1/PPAR $\gamma$ in 
HFD-mediated groups (Fig. 6).

In conclusion, the interaction of FoxO1 with PPAR $\gamma$ leads to hepatic lipogenesis in $d b / d b$ mice. In addition, PAR2/ $\beta$-arrestinmediated Akt signaling induced lipid accumulation in $\mathrm{db} / \mathrm{db}$ mice (Fig. 4D). This study showed that the pivotal role of FoxO1 interaction in hepatic steatosis can be observed by PAR2 signaling pathway activation in obese mice.

\section{CONFLICTS OF INTEREST}

No potential conflict of interest relevant to this article was reported.

\section{ACKNOWLEDGMENTS}

This work was supported by a National Research Foundation (NRF) grant funded by the Korean government (NRF-2018R1A2A3075425). Furthermore, this research was supported by the Basic Science Research Program through the NRF funded by the Ministry of Education (NRF-2018R1A6A3A11046180). We also take this opportunity to thank the Aging Tissue Bank (NRF-2015M3A9B8029074) for providing aged tissues.

\section{AUTHOR CONTRIBUTIONS}

Conception or design: D.H.K., Y.R.K., H.Y.C. Acquisition, analysis, or interpretation of data: E.J.B., S.H., S.G.N., B.M.K., S.H.J. Drafting the work or revising: H.J.J., J.Y.L. Final approval of the manuscript: D.H.K., H.Y.C.

\section{ORCID}

Dae Hyun Kim https://orcid.org/0000-0003-4391-5502

Hae Young Chung https://orcid.org/0000-0002-3215-8828

\section{REFERENCES}

1. Jung UJ, Choi MS. Obesity and its metabolic complications: the role of adipokines and the relationship between obesity, inflammation, insulin resistance, dyslipidemia and nonalcoholic fatty liver disease. Int J Mol Sci 2014;15:6184-223.

2. Groneberg DA, Franke K, Klingelhofer D, Schwarzer M, Ohlendorf D. Density equalizing mapping of obesity: analysis of a global epidemic. Z Gastroenterol 2015;53:553-61.

3. Newell-Fugate AE. The role of sex steroids in white adipose tissue adipocyte function. Reproduction 2017;153:R133-49.
4. Palmer BF, Clegg DJ. The sexual dimorphism of obesity. Mol Cell Endocrinol 2015;402:113-9.

5. Accili D, Arden KC. FoxOs at the crossroads of cellular metabolism, differentiation, and transformation. Cell 2004;117: 421-6.

6. Karger S, Weidinger C, Krause K, Sheu SY, Aigner T, Gimm O, et al. FOXO3a: a novel player in thyroid carcinogenesis? Endocr Relat Cancer 2009;16:189-99.

7. Barthel A, Schmoll D, Unterman TG. FoxO proteins in insulin action and metabolism. Trends Endocrinol Metab 2005;16:183-9.

8. Biggs WH 3rd, Meisenhelder J, Hunter T, Cavenee WK, Arden KC. Protein kinase B/Akt-mediated phosphorylation promotes nuclear exclusion of the winged helix transcription factor FKHR1. Proc Natl Acad Sci U S A 1999;96:7421-6.

9. Kawamori D, Kaneto H, Nakatani Y, Matsuoka TA, Matsuhisa M, Hori M, et al. The forkhead transcription factor Foxo1 bridges the JNK pathway and the transcription factor PDX-1 through its intracellular translocation. J Biol Chem 2006;281:1091-8.

10. Martinez SC, Tanabe K, Cras-Meneur C, Abumrad NA, Bernal-Mizrachi E, Permutt MA. Inhibition of Foxo1 protects pancreatic islet beta-cells against fatty acid and endoplasmic reticulum stress-induced apoptosis. Diabetes 2008; 57:846-59.

11. Van Der Heide LP, Hoekman MF, Smidt MP. The ins and outs of FoxO shuttling: mechanisms of FoxO translocation and transcriptional regulation. Biochem J 2004;380(Pt 2):297-309.

12. Lehrke M, Lazar MA. The many faces of PPARgamma. Cell 2005;123:993-9.

13. Matsusue K, Kusakabe T, Noguchi T, Takiguchi S, Suzuki T, Yamano S, et al. Hepatic steatosis in leptin-deficient mice is promoted by the PPARgamma target gene Fsp27. Cell Metab 2008; 7:302-11.

14. Wierzbicki M, Chabowski A, Zendzian-Piotrowska M, Gorski J. Differential effects of in vivo PPAR alpha and gamma activation on fatty acid transport proteins expression and lipid content in rat liver. J Physiol Pharmacol 2009;60:99106.

15. Kim DH, Zhang T, Lee S, Calabuig-Navarro V, Yamauchi J, Piccirillo A, et al. FoxO6 integrates insulin signaling with MTP for regulating VLDL production in the liver. Endocrinology 2014;155:1255-67.

16. Bose SK, Kim H, Meyer K, Wolins N, Davidson NO, Ray R. Forkhead box transcription factor regulation and lipid accu- 
mulation by hepatitis C virus. J Virol 2014;88:4195-203.

17. Polvani S, Tarocchi M, Galli A. PPAR $\gamma$ and oxidative stress: $\operatorname{con}(\beta)$ catenating NRF2 and FOXO. PPAR Res 2012;2012: 641087.

18. Kim DH, Lee B, Kim MJ, Park MH, An HJ, Lee EK, et al. Molecular mechanism of betaine on hepatic lipid metabolism: inhibition of forkhead box O1 (FoxO1) binding to peroxisome proliferator-activated receptor gamma (PPAR $\gamma)$. J Agric Food Chem 2016;64:6819-25.

19. Haslam DW, James WP. Obesity. Lancet 2005;366:1197209.

20. Lin HV, Accili D. Hormonal regulation of hepatic glucose production in health and disease. Cell Metab 2011;14:9-19.

21. Rothmeier AS, Ruf W. Protease-activated receptor 2 signaling in inflammation. Semin Immunopathol 2012;34:133-49.

22. Badeanlou L, Furlan-Freguia C, Yang G, Ruf W, Samad F. Tissue factor-protease-activated receptor 2 signaling promotes diet-induced obesity and adipose inflammation. Nat Med 2011;17:1490-7.

23. Srinivasan R, Ozhegov E, van den Berg YW, Aronow BJ, Franco RS, Palascak MB, et al. Splice variants of tissue factor promote monocyte-endothelial interactions by triggering the expression of cell adhesion molecules via integrin-mediated signaling. J Thromb Haemost 2011;9:2087-96.

24. Park MK, Cho MK, Kang SA, Kim BY, Yu HS. The induction of the collagen capsule synthesis by Trichinella spiralis is closely related to protease-activated receptor 2 . Vet Parasitol 2016;230:56-61.

25. Coudriet GM, Delmastro-Greenwood MM, Previte DM, Marre ML, O'Connor EC, Novak EA, et al. Treatment with a catalytic superoxide dismutase (SOD) mimetic improves liver steatosis, insulin sensitivity, and inflammation in obesity-induced type 2 diabetes. Antioxidants (Basel) 2017;6:85.

26. Guo S. Molecular basis of insulin resistance: the role of IRS and foxol in the control of diabetes mellitus and its complications. Drug Discov Today Dis Mech 2013;10:e27-33.

27. Shearer AM, Rana R, Austin K, Baleja JD, Nguyen N, Bohm A, et al. Targeting liver fibrosis with a cell-penetrating protease-activated receptor-2 (PAR2) pepducin. J Biol Chem 2016;291:23188-98.

28. Kim DH, Lee B, Lee J, Kim ME, Lee JS, Chung JH, et al. FoxO6-mediated IL-1 $\beta$ induces hepatic insulin resistance and age-related inflammation via the TF/PAR2 pathway in aging and diabetic mice. Redox Biol 2019;24:101184.

29. Qu S, Altomonte J, Perdomo G, He J, Fan Y, Kamagate A, et al. Aberrant forkhead box $\mathrm{O} 1$ function is associated with impaired hepatic metabolism. Endocrinology 2006;147: 5641-52.

30. Cook JR, Matsumoto M, Banks AS, Kitamura T, Tsuchiya K, Accili D. A mutant allele encoding DNA binding-deficient FoxO1 differentially regulates hepatic glucose and lipid metabolism. Diabetes 2015;64:1951-65.

31. Balaban RS, Nemoto S, Finkel T. Mitochondria, oxidants, and aging. Cell 2005;120:483-95.

32. Panici JA, Harper JM, Miller RA, Bartke A, Spong A, Masternak MM. Early life growth hormone treatment shortens longevity and decreases cellular stress resistance in long-lived mutant mice. FASEB J 2010;24:5073-9.

33. Kops GJ, Dansen TB, Polderman PE, Saarloos I, Wirtz KW, Coffer PJ, et al. Forkhead transcription factor FOXO3a protects quiescent cells from oxidative stress. Nature 2002;419: 316-21.

34. Ables GP. Update on PPAR $\gamma$ and nonalcoholic fatty liver disease. PPAR Res 2012;2012:912351.

35. Matsumoto M, Han S, Kitamura T, Accili D. Dual role of transcription factor FoxO1 in controlling hepatic insulin sensitivity and lipid metabolism. J Clin Invest 2006;116: 2464-72.

36. Inoue M, Ohtake T, Motomura W, Takahashi N, Hosoki Y, Miyoshi S, et al. Increased expression of PPARgamma in high fat diet-induced liver steatosis in mice. Biochem Biophys Res Commun 2005;336:215-22.

37. Matsusue K, Haluzik M, Lambert G, Yim SH, Gavrilova O, Ward JM, et al. Liver-specific disruption of PPARgamma in leptin-deficient mice improves fatty liver but aggravates diabetic phenotypes. J Clin Invest 2003;111:737-47.

38. Yu S, Matsusue K, Kashireddy P, Cao WQ, Yeldandi V, Yeldandi AV, et al. Adipocyte-specific gene expression and adipogenic steatosis in the mouse liver due to peroxisome proliferator-activated receptor gammal (PPARgamma1) overexpression. J Biol Chem 2003;278:498-505.

39. Navab M, Gharavi N, Watson AD. Inflammation and metabolic disorders. Curr Opin Clin Nutr Metab Care 2008;11: 459-64.

40. Galgani JE, Uauy RD, Aguirre CA, Diaz EO. Effect of the dietary fat quality on insulin sensitivity. Br J Nutr 2008;100: 471-9.

41. Tereshina EV. Metabolic abnormalities as a basis for agedependent diseases and aging? State of the art. Adv Gerontol 2009;22:129-38.

42. Noguerol J, Roustan PJ, N'Taye M, Delcombel L, Rolland C, Guiraud L, et al. Sexual dimorphism in PAR2-dependent 
regulation regulation of primitive colonic cells. Biol Sex Differ 2019; 10:47.

43. Wang J, Chakrabarty S, Bui Q, Ruf W, Samad F. Hematopoietic tissue factor-protease-activated receptor 2 signaling promotes hepatic inflammation and contributes to pathways of gluconeogenesis and steatosis in obese mice. Am J Pathol 2015;185:524-35. 